Gut, 1980, 21, 1062-1067

\title{
Serum gastrin in patients with chronic renal failure
}

\author{
I L TAYLOR,* R A SELLS, R B McCONNELL, AND G J DOCKRAY \\ From the Physiological Laboratory and Department of Surgery, University of Liverpool, England, and CURE, \\ VA Wadsworth Hospital, Los Angeles, USA
}

SUMMARY The realisation that circulating gastrin is heterogeneous necessitates a reappraisal of gastrin's role in the increased incidence of duodenal ulcer disease that occurs in chronic renal failure. Radioimmunoassays employing region-specific antisera have been used to examine renal and extrarenal factors controlling serum gastrin concentration in patients with chronic renal failure. The present study has shown that basal serum gastrin concentrations measured with a carboxyl-terminal specific antibody were significantly higher in eight patients with chronic renal failure treated by dietary restriction $(388 \pm 196 \mathrm{pM})$ than in 14 patients with chronic renal failure treated by haemodialysis $(28.7 \pm 4.6 \mathrm{pM})$. However, basal gastrin concentrations in both groups of patients were significantly higher than in 25 normal subjects $(12.3 \pm 1.8 \mathrm{pM})$ and showed significant negative correlations with maximal gastric acid secretion $(\mathrm{P}<0.01)$. Markedly raised basal gastrin concentrations were observed only in chronic renal failure patients who were also achlorhydric. Although the peak postprandial increment in big gastrin concentration in 11 chronic renal failure patients $(34 \cdot 0 \pm$ $7.5 \mathrm{pM})$ was significantly greater $(\mathrm{P}<0.05)$ than in 25 normal subjects $(19.5 \pm 4.6 \mathrm{pM})$, the little gastrin responses were not significantly different. In addition, clearance of exogenous little gastrin was similar in four chronic failure patients (clearance half time: $8.1 \pm 0.7 \mathrm{~min}$ ) and four normal subjects (clearance half time: $6 \cdot 5 \pm 1 \cdot 2 \mathrm{~min}$ ). These studies suggest that the human kidney is unimportant in the metabolism of little gastrin. As circulating little gastrin is six times more potent than big gastrin in stimulating acid secretion, these studies suggest that the raised gastrin concentrations observed in patients with chronic renal failure have little significance in terms of their increased incidence of duodenal ulcer disease.

An increased incidence of duodenal ulcer disease, hyperchlorhydria, ${ }^{1}$ and hypergastrinaemia ${ }^{23}$ has been described in patients with chronic renal failure (CRF). However, it is unclear whether the hypergastrinaemia is causally related to either the hyperchlorhydria or the propensity for these patients to develop ulcers. Studies in the dog have demonstrated a significant arteriovenous difference in gastrin concentrations across the kidney ${ }^{4}$ and a decreased clearance of exogenous gastrin from the circulation after bilateral nephrectomy. ${ }^{5}$ As a result of these findings it has been assumed that the hypergastrinaemia observed in CRF patients is a reflection of altered metabolism. However, this supposition has not been confirmed by the direct measurement of the metabolic clearance of gastrin in patients with chronic renal failure.

*Address for reprint requests: Ian L Taylor, Sepulveda VA Hospital (111G), 16111 Plummer Street, Sepulveda, CA 91343, USA.

Received for publication 16 July 1980
Our understanding of the relationship between gastrin and acid secretion in CRF is complicated by the existence of multiple forms of gastrin ${ }^{6}$ which differ markedly in their rate of clearance from the circulation and their ability to stimulate acid secretion. ${ }^{78}$ The major circulating components of gastrin in man are $\mathrm{G} 17$ and G34; circulating G17 is six times more potent than G34 in stimulating acid secretion. This difference in biological potency necessitates a separate measurement of these two forms in CRF patients. Unfortunately, although conventional anti-gastrin antisera measure both G17 and G34 they are incapable of distinguishing between them. ${ }^{9}$ The purpose of the present study was to delineate factors, both renal and extrarenal, which regulate serum gastrin concentrations in CRF patients. In particular we sought to determine the relationship between acid secretion and basal gastrin concentrations in CRF patients. In addition, we have used a specific radioimmunoassay to measure the $\mathrm{G} 17$ response to a meal in normal subjects 
and CRF patients. Lastly, the metabolic clearance rate and metabolic half life of exogenous G17 have been measured in CRF patients and normal subjects.

\section{Methods}

\section{PATIENTS}

Basal blood samples were obtained from 22 CRF patients and 60 subjects without peptic ulcer disease or renal disease immediately preceding an acid output study $(6 \mu \mathrm{g} / \mathrm{kg}$ pentagastrin subcutaneously). Fourteen of the CRF patients were being treated by haemodialysis and eight by dietary restriction, either because their CRF was stable or as a temporary measure before starting a haemodialysis programme. All patients studied had creatinine clearances of less than $20 \mathrm{ml} / \mathrm{min}$.

The gastrin response to a standard meal was measured in 25 normal subjects with no history of gastrointestinal or renal disease, and in 11 CRF patients who were being treated by periodic haemodialysis. Two of the CRF patients were anephric and four had duodenal ulcers demonstrated by endoscopy or at subsequent operation.

Finally, the metabolic clearance rate and metabolic half life of exogenous $\mathrm{G} 17$ has been measured and compared in four normal subjects and four CRF patients. All four CRF patients had basal gastrin concentrations under $50 \mathrm{pM}$ but had enhanced gastrin responses to food with a mean peak increment of $42 \pm 10 \mathrm{pM}$, which compares with $25 \pm 4 \mathrm{pM}$ in 25 normal subjects. ${ }^{10}$ All four CRF patients were being treated by periodic haemodialysis; one of the patients was anephric.

Informed consent was obtained from all the patients and this study was approved by the Research Committee at The Royal Infirmary, Liverpool, England (1975).

\section{Standard meal}

Each subject fasted from midnight. The next morning blood samples were taken from an indwelling intravenous needle 15 and five minutes before the subject ate a standard meal. The meal, consisting of two hard boiled eggs, one piece of dry toast, and a cup of beef extract (two Oxo cubes in $120 \mathrm{ml}$ water), was eaten over a period of 10 minutes. Blood samples were taken at 20 minute intervals for 60 minutes, and 15 minute intervals for another hour.

\section{Metabolism of G17}

Four normal subjects and four patients with CRF received a 60 minute infusion of synthetic human G17 (ICI pharmaceuticals, Alderley Park, Macclesfield, Cheshire, England) $(295 \mathrm{pmol} / \mathrm{kg} / \mathrm{h})$. Blood samples were taken for gastrin measurements 30 and five minutes before starting the infusion of G17 and at 10, 20,30, 40, 45, 50, and 55 minutes thereafter. Additional samples were taken two, four, seven, $12,15,20$, and 30 minutes after stopping the infusion to measure the disappearance of G17 from the circulation. Basal gastrin concentrations were subtracted from all measurements of gastrin during the infusions and during the estimation of the disappearance of G17. The metabolic clearance rate (MCR) in $\mathrm{ml} / \mathrm{kg} / \mathrm{min}$ was calculated by dividing the infused dose of $\mathrm{pmol} / \mathrm{kg} / \mathrm{min}$ by the plateau increment in $\mathrm{pM} .{ }^{7}$ Single exponential disappearance curves were obtained by plotting the natural logarithm of the increment in serum gastrin against time. Linear regression yielded the slope, $-\mathrm{k}$, and the clearance half-time $\left(T_{1} \frac{1}{2}\right)$ was calculated from the equation $T \frac{1}{2}=0.693 / \mathrm{k}^{7}$ The volume of distribution $(\mathrm{V})$ as a fraction of body weight was calculated by the use of the plateau principle described by Goldstein et al. ${ }^{11}$ from the formula $\mathrm{V}=\mathrm{D} / \mathrm{Pk}$, where $\mathrm{D}$ is the dose of G17 in $\mathrm{pmol} / \mathrm{kg} / \mathrm{min}$ and $\mathrm{P}$ is the steady state blood level of gastrin in $\mathrm{pM}$.

\section{Radioimmunoassay $(R I A)$}

Serum gastrin concentrations were estimated by RIA according to published methods. ${ }^{912}$ Two antisera with different specificities were employed. One antiserum (L6) has been shown to have almost absolute specificity for G17 and shows negligible cross-reactivity with G34 and with fragments of G17 with amino acid deletions at either the carboxyl- or amino-terminus. ${ }^{13}$ The second antiserum (1296) is specific for the carboxyl-terminus of G17 and therefore measures G17, G34, and other gastrin variants with a carboxyl-terminus similar to G17.9 $\mathrm{Ab} 1296$ was used to study the metabolism of G17 in the normal subjects and patients with renal failure. Both Ab L6 and 1296 were used to study the gastrin response to the standard meal in the two groups. Ab L6 was used to measure the G17-L1 response and an indirect estimate of $\mathrm{G} 34$ concentrations (estimated G34) was obtained from the difference of measurements made with L6 and 1296. These methods have been previously validated. ${ }^{13}$ The immunochemical potency of G34 with 1296 is about 0.6 compared with $\mathrm{G} 17,{ }^{9}$ and estimates of G34 concentrations were corrected to take account of this. Pure natural human unsulphated G17 was used as a standard for all assays.

\section{Results}

BASAL GASTRIN CONCENTRATIONS IN CRF PATIENTS

Basal gastrin concentrations measured with the carboxyl-terminal specific antisera, Ab 1296, were 


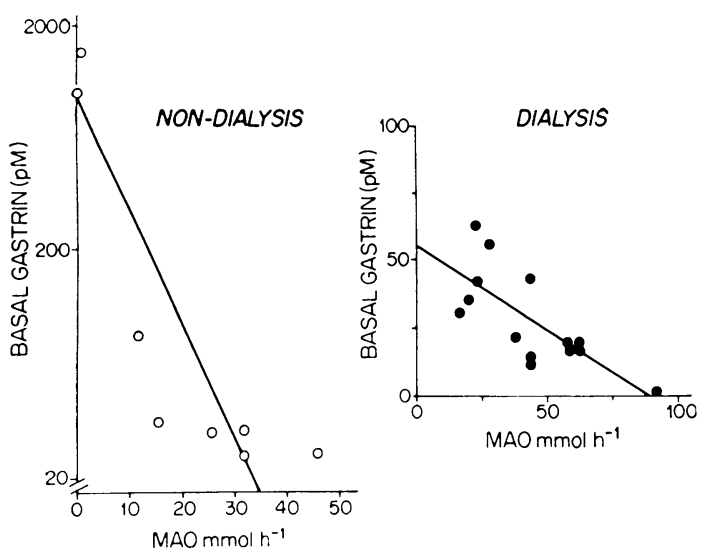

Fig. 1 The correlation between maximal acid output and total carboxyl-terminal immunoreactive gastrin in basal serum of (left) eight CRF patients on dietary restriction alone, (right) 14 patients on haemodialysis.

significantly $(\mathrm{P}<0.01)$ higher in the eight $\mathrm{CRF}$ patients treated by dietary restriction $(338 \pm 196 \mathrm{pM})$ compared with the 14 patients treated by haemodialysis $(28 \pm 4 \mathrm{pM})$. Basal gastrin concentrations in both subgroups were significantly higher $(\mathrm{P}<0.05)$ than in 25 normal subjects $(12 \cdot 3 \pm 1 \cdot 8 \mathrm{pM})$. Basal acid output (BAO) was higher in the haemodialysis treated patients $(2.7 \pm 0.7 \mathrm{mmol} / \mathrm{h})$ than in the CRF patients on diet alone $(0.94 \pm 5.8 \mathrm{mmol} / \mathrm{h})$. In addition, maximal acid output (MAO) was significantly higher $(\mathrm{P}<0.01)$ in the CRF patients on haemodialysis $(45 \pm 5 \mathrm{mmol} / \mathrm{h})$ than in those treated by dietary restriction $(21 \cdot 4 \pm 5.8 \mathrm{mmol} / \mathrm{h})$. No significant correlation was seen between BAO and basal serum gastrin concentration in either CRF subgroup or the population as a whole. However, there was a

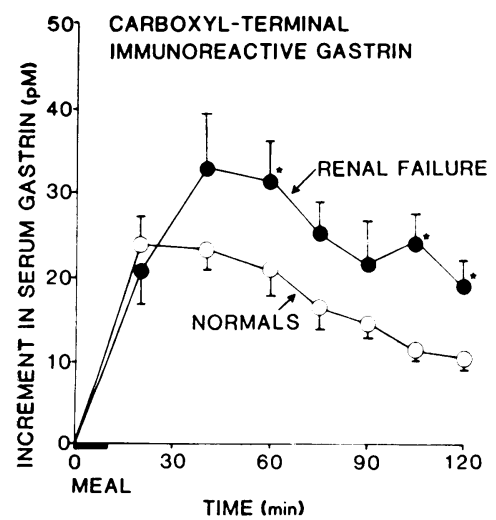

Fig. 2 Total carboxyl-terminal immunoreactive gastrin response to a meal in 25 normal subjects and 11 CRF patients. significant negative correlation $(\mathrm{P}<0.01)$ between MAO and basal serum gastrin concentrations in both subgroups (haemodialysis $r=-0.759$, nonhaemodialysis $r=-0 \cdot 795$, Fig. 1). No significant correlation between basal gastrin concentration and MAO $(r=-0.04 ; \mathrm{P}<0.05)$ was found in 60 subjects without renal disease or peptic ulcer disease ${ }^{14}$ (BAO 2.3 $\pm 0 \cdot 5 \mathrm{MAO} 25 \pm 3 \mathrm{mmol} / \mathrm{h}$; basal gastrin $19 \pm 2 \mathrm{pM}$ ). Two CRF patients, who were treated by dietary restriction alone, had basal gastrin concentrations of 1350 and $940 \mathrm{pM}$ and were found to be achlorhydric. One CRF patient on haemodialysis had no detectable gastrin immunoreactivity in his basal serum and had a MAO of $92 \mathrm{mmol} / \mathrm{h}$. Despite the large secretory capacity, this patient did not have peptic ulcer disease.

\section{GASTRIN RESPONSE TO STANDARD MEAL}

In the group of 11 CRF patients treated by haemodialysis who had the standard meal, fasting gastrin concentration measured by Ab 1296 was $28 \pm 4 \cdot 2$ $\mathrm{pM}$, significantly higher than in the 25 normal subjects $(12 \cdot 3 \pm 1 \cdot 8 \mathrm{pM})$.

Figure 2 shows the increment in total gastrin as measured by the carboxyl-terminal specific antibody, 1296, in normal subjects and patients with chronic renal failure treated by haemodialysis. The peak increment, in carboxyl-terminal immunoreactive gastrin was higher in the renal failure group $(33.5 \pm 7 \cdot 2 \mathrm{pM})$ than in the normal subjects $(24.2 \pm$ $4.0 \mathrm{pM})$. The peak increment occurred later in the CRF group and the response was greater and more prolonged. The increment in carboxyl-terminal immunoreactive gastrin concentrations was significantly higher $(\mathrm{P}<0.05)$ in the CRF group compared with normal at 60,105 and 120 minutes. In the 11 CRF patients, no significant correlation was observ-

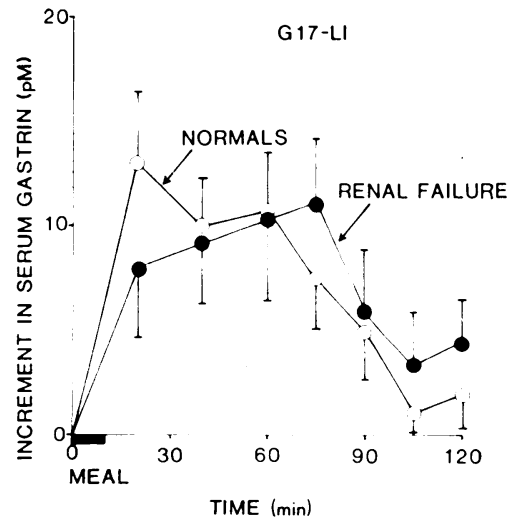

Fig. 3 G17-L1 response to a meal in 25 normal subjects and 11 CRF patients. 


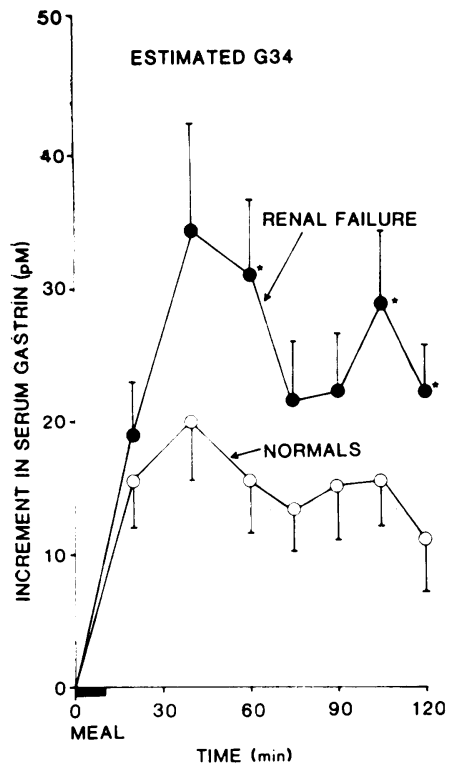

Fig. 4 Estimated $G 34$ response to a meal in 25 normal subjects and 11 CRF patients.

ed between basal gastrin concentration and the peak meal response. Seven of the subjects fed the standard meal also had acid secretory studies. In this subgroup a negative correlation $(r=-0.656)$ between the peak gastrin response to a meal and MAO was observed. However, this was just short of the value needed to reach statistical significance.

In contrast, there was no significant difference in the G17-L1 response to the meal between the two groups at any time period (Fig. 3). The peak increment in G17-L1 was $10.8 \pm 3.3 \mathrm{pM}$ in the CRF group, compared with $13.5 \pm 3.0 \mathrm{pM}$ in the normals.

Figure 4 shows the increment in estimated G34 in both groups. The response was greater and more prolonged in the renal failure group, the difference reaching statistical significance at 60,105 , and 120 minutes $(P<0.05)$. The peak increment in estimated G34 was significantly higher $(\mathrm{P}<0.05)$ in the patients with CRF $(34.0 \pm 7.5 \mathrm{pM})$ than in the normal subjects $(19 \cdot 5-4.0 \mathrm{pM})$.

The mean peak increment in G17-L1 concentrations in the two anephric patients was $9.0 \mathrm{pM}$ compared with $10.5 \mathrm{pM}$ in the other CRF patients; the peak increment in carboxyl-terminal immunoreactive gastrin concentration was $33 \mathrm{pM}$ in the anephric patients compared with $36 \mathrm{pM}$ in the others. Neither of the anephric patients had peptic ulcer disease.

There were no statistically significant differences between the responses in the four CRF patients with duodenal ulcer and the other patients without ulcer. The mean peak increment in G17-L1 concentration

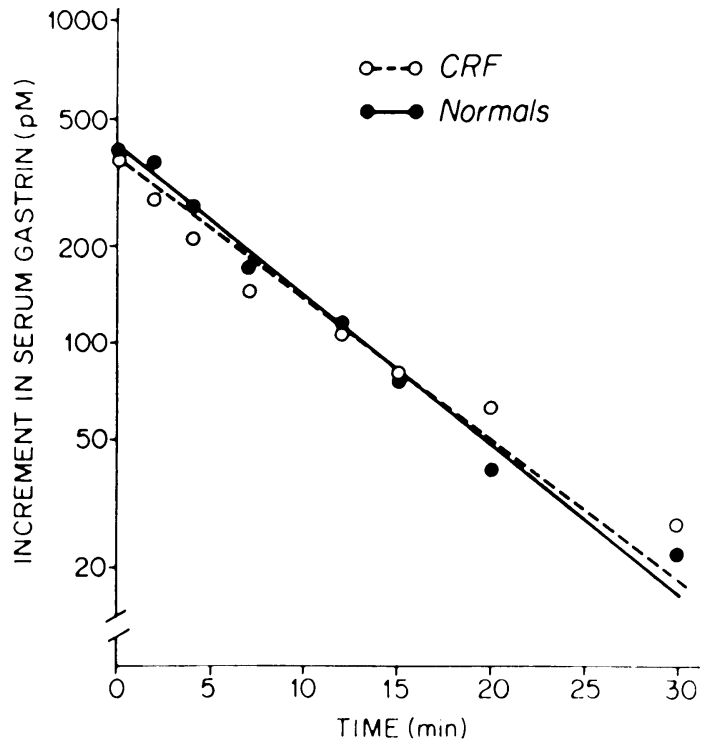

Fig. 5 Disappearance of $G 17$ in four CRF patients and four normal subjects.

in the ulcer group was $11.5 \mathrm{pM}$ compared with $11.4 \mathrm{pM}$ in the non-ulcer CRF patients; the peak increment in carboxyl-terminal immunoreactivity was $40 \mathrm{pM}$ in those with duodenal ulcer compared with $31 \mathrm{pM}$ in the patients without peptic ulcer.

\section{METABOLISM OF G 17}

The clearance rate of $\mathrm{G} 17$ was $18 \cdot 4 \pm 7 \cdot 1 \mathrm{ml} / \mathrm{kg} / \mathrm{min}$ in the four CRF patients and was not statistically different from that seen in the four normal subjects $(12.9 \pm 2.0 \mathrm{ml} / \mathrm{kg} / \mathrm{min})$. The distribution volume was similar in both groups $(0.096 \pm 0.0361 / \mathrm{kg}$ in the CRF and $0 \cdot 110 \pm 0.0261 / \mathrm{kg}$ in normal subjects).

Figure 5 shows the disappearance of G17 in the two groups when the infusion was ended. The disappearance half time calculated from the mean data was $8 \cdot 1 \pm 0.7 \mathrm{~min}$ in the CRF patients and $6.5 \pm 1 \cdot 2$ $\mathrm{min}$ in the normal subjects. This difference was not statistically significant.

\section{Discussion}

The present study has shown that patients with chronic renal failure have higher than normal concentrations of total carboxyl-terminal immunoreactive gastrin in basal serum, confirming previous reports by other workers. ${ }^{2}{ }^{3} \mathrm{We}$ have also shown that CRF patients on haemodialysis have significantly lower basal gastrin concentrations than those treated by dietary restriction alone, probably reflecting the difference in rates of acid secretion in the two groups 
-that is, those treated by diet alone had lower basal and maximal rates of acid secretion. However, in both subgroups there was a significant negative correlation between basal gastrin concentration and MAO. The higher rates of acid secretion observed in the haemodialysis treated patients suggests that haemodialysis removes an inhibitor of acid secretion. We observed markedly raised gastrin concentrations in only two of the diet restricted CRF group who were also achlorhydric. Hallgren et al. ${ }^{15}$ found that $10 \%(3 / 31)$ of patients on maintenance dialysis had gastrin concentrations in the ZollingerEllison range, but did not report acid secretory data in these patients, so it is unclear whether these patients also had hypergastrinaemia secondary to achlorhydria.

In agreement with other workers ${ }^{1617}$ we found that CRF patients on haemodialysis have greater than normal total carboxyl-terminal immunoreactive gastrin responses to food. The postprandial concentrations of estimated G34 were found to be raised in the CRF patients. This fraction is predominantly made up of G34 but will contain other gastrin components which share the same immunochemical carboxyl-terminal structure as G17-for example, G14 and component I. As circulating G34 is only one-sixth as potent in stimulating acid secretion as G17, the hypergastrinaemia seen in CRF patients probably has little significance in terms of the increased incidence of duodenal ulcer disease seen in these patients. In contrast, the G17 response to feeding as measured by specific radioimmunoassay was found to be indistinguishable in CRF patients from that seen in normal subjects. This finding suggests that either the human kidney is relatively unimportant in the metabolism of G17 or that the synthesis or secretion of G17 is inhibited selectively in CRF patients. Our demonstration that the metabolic clearance rate and metabolic half life of G17 is normal in CRF patients provides direct evidence for the first hypothesis. However, this observation is at variance with the studies in the $\operatorname{dog}^{5}$ and rat $^{18}$ where the metabolic clearance rate of G17 was shown to be markedly reduced by nephrectomy. These apparent discrepancies suggest either species differences or differences in the handling of gastrin in acute and chronic renal failure. Although this is the first report of metabolic studies with exogenous gastrin in CRF patients, Schjonsby and Hillassen ${ }^{19}$ could find no significant arteriovenous difference in serum gastrin concentrations across the kidney in three normal subjects. A mechanism which offers an explanation for the equally rapid rate of removal of exogenous G17 from the circulation of normal subjects and CRF patients lies in Strunz et al.' $\mathrm{s}^{20}$ demonstration that $\mathrm{G} 17$ is removed by most, if not all, the capillary beds of the body, so that the loss of the kidneys may be compensated for by increased clearance by other organs.

In summary, patients with chronic renal failure have been shown to have an increased incidence of duodenal ulcer disease and raised basal serum gastrin concentrations. ${ }^{23}$ Although this combination suggests a causal relationship, our findings do not support this conjecture. Thus, in CRF patients basal gastrin concentration exhibited a negative correlation with maximal acid output and markedly raised gastrin concentrations were observed only in CRF patients who were also achlorhydric. In addition, basal and meal stimulated gastrin concentrations were not significantly different in CRF patients with duodenal ulcers when compared with CRF patients without ulcer disease. Finally, we have demonstrated that the metabolic clearance of the most biologically potent form of gastrin $\mathrm{G} 17$, is normal in CRF patients. These findings suggest that gastrin is not responsible for the increased incidence of duodenal ulcer disease observed in chronic renal failure, and that the markedly raised basal gastrin concentrations sometimes seen in patients with chronic renal failure are associated with decreased rather than increased acid secretions.

This work was supported by grants from the Medical Research Council of Great Britain and the Nuffield Foundation. The authors are indebted to Mrs Elaine Clarke and Miss Carol Higgins for skilled technical assistance. We would also like to thank Professor M I Grossman and Professor J H Walsh for their many helpful suggestions during the preparation of this manuscript.

\section{References}

${ }^{1}$ Shepherd AMM, Stewart WK, Wormsley KG. Peptic ulceration in chronic renal failure. Lancet 1973; 1: $1357-9$.

${ }^{2}$ Maxwell JG, Moore JG, Dixon J, Stevens LE. Gastrin levels in anephric patients. Surg Forum 1971 ; 22: 305-6.

${ }^{3}$ Korman MG, Laver MC, Hansky J. Hypergastrinaemia in chronic renal failure. Br Med J 1972; 1: 209-10.

${ }^{4}$ Booth RAD, Reeder DD, Hjelmquist UB, Brandt EM, Thompson JC. Renal inactivation of endogenous gastrin in dogs. Arch Surg 1973; 106: 851-4.

${ }^{5}$ Clendinnen BG, Reeder DD, Brandt EN, Thompson JC. Effect of nephrectomy on the rate and pattern of the disappearance of exogenous gastrin in dogs. Gut 1973; 14: 462-7.

${ }^{6}$ Gregory RA, Tracy JH. The chemistry of the gastrins: some recent advances. In: Thompson JC, ed. Gastrointestinal hormones. Austin and London: University of Texas Press, 1975: 13-24. 
${ }^{7}$ Walsh JH, Debas HT, Grossman MI. Pure human big gastrin: immunochemical properties, disappearance half-time, and acid-stimulating action in dogs. $J$ Clin Invest $1974 ; 54: 477-85$.

${ }^{8}$ Walsh JH, Isenberg JI, Ansfield J, Maxwell V. Clearance and acid-stimulating action of human big and little gastrins in duodenal ulcer subjects. J Clin Invest 1976; 57: 1125-31.

${ }^{9} \mathrm{Walsh}$ JH. Radioimmunoassay of gastrin. In: Rothfeld $\mathrm{B}$, ed. Nuclear medicine in vitro. Philadelphia and Toronto: JB Lippincott, 1974; 17: 213-48.

${ }^{10}$ Taylor IL, Dockray GJ, Calam J, Walker R. Big and little gastrin responses to food in duodenal ulcer patients and normal subjects. Gut 1979; 20: 957-62.

${ }^{11}$ Goldstein A, Aronow L, Kalman M. The time course of drug action. In: Principles of drug action. New York: Harper and Row, 1974: 301-55.

${ }^{12}$ Yalow RS, Berson SA. Radioimmunoassay of gastrin. Gastroenterology 1970; 58: 1-14.

${ }^{13}$ Dockray GJ, Taylor IL. Heptadecapeptide gastrin: measurement in blood by specific radioimmunoassay. Gastroenterology 1976; 71: 971-7.
${ }^{14}$ Taylor IL. In: Region specific antibodies and the study of gastrin. Ph.D. Thesis: Liverpool University, 1976.

${ }^{15}$ Hallgren R, Karlsson FA, Lundqvist G. Serum level of immunoreactive gastrin: influence of kidney function. Gut 1978; 19: 207-13.

${ }^{16}$ Hansky J, King RW, Holdsworth S. Serum gastrin in chronic renal failure. In: Thompson JC, ed. Gastrointestinal hormones. Austin and London: University of Texas Press, 1975: 115-24.

${ }^{17}$ Gedde-Dahl D. Serum gastrin response to food stimulation in male azotemic patients. Scand J Gastroenterol 1975; 9: 41-7.

${ }^{18}$ Davidson WD, Moore TC, Shippey W, Conovaloff AJ. Effect of bilateral nephrectomy and bilateral ureteral ligation on serum gastrin levels in the rat. Gastroenterology 1974; 66: 522-5.

${ }^{19}$ Schjonsby $\mathrm{H}$, Willassen Y. Renal extraction of endogenous gastrin in patients with normal renal function. Scand J Gastroenterol 1977; 12: 205-7.

${ }^{20}$ Strunz UT, Walsh JH, Grossman MI. Removal of gastrin by various organs. Gastroenterology 1978; 74: 32-3. 